\title{
Thermographic analysis of dual-phase steel under quasi-static and dynamic tension
}

\author{
S. Kołodziej ${ }^{1 *}$, G. Weber ${ }^{2}$, A. Czulak $^{3}$, W. Ozgowicz ${ }^{4}$ \\ ${ }^{1}$ University of Silesia in Katowice, Institute of Materials Science, ul. 75 Putku Piechoty 1, 41-500 Chorzów, Poland \\ ${ }^{2}$ Leichtbau-Zentrum Sachsen GmbH (LZS), Marschnerstr. 39, 01307 Dresden, Germany \\ ${ }^{3}$ Technische Universität Dresden, Institute of Lightweight Engineering and Polymer Technology (ILK), \\ Holbeinstr. 3, 01307 Dresden, Germany \\ ${ }^{4}$ Silesian University of Technology, Institute of Engineering Materials and Biomaterials, \\ ul. Konarskiego 18a, 44-100 Gliwice, Poland
}

Received 11 January 2018, received in revised form 27 September 2018, accepted 3 December 2018

\begin{abstract}
The work presents a study on temperature changes during tensile tests of high-strength dual-phase steel, performed with different strain rates, $\dot{\varepsilon}_{1}=3.3 \times 10^{-3} \mathrm{~s}^{-1}$ and $\dot{\varepsilon}_{2}=33 \mathrm{~s}^{-1}$, at room temperature, making use of a high-resolution thermographic camera. It has been shown that with increasing strain rate the ultimate tensile strength grows, from ca. 1305 to ca. $1326 \mathrm{MPa}$, whereby the average strain values decrease from ca. 7.9 to ca. $7.2 \%$. The temperature of the specimens stretched with the lower strain rate grows during the tensile test by about $32^{\circ} \mathrm{C}$, whereas, in the case of the specimens stretched with a higher strain rate, by about $98^{\circ} \mathrm{C}$. Moreover, the precise analysis of the temperature profiles, registered with the thermographic camera, indicated a significant temperature drop preceding the rupture of specimens by about $5 \%$ of the maximum temperature value.
\end{abstract}

K e y words: thermographic measurements, infrared camera, tensile test, high-speed deformation, dual-phase steels

\section{Introduction}

Thermographic investigations of construction materials, in particular from the AHSS (Advanced High Strength Steels) group, deformed at high strain rates $(\dot{\varepsilon})$, are considered to be of great interest in many fields of technology, especially in the automotive industry and other transport branches. The main reason for this interest is the fact that a great amount of the plastic deformation energy causes, despite structural changes in the material, a distinct thermal effect observed as a temperature rise of certain construction elements $[1,2]$. The temperature increase can be very high, leading e.g. to thermal decomposition in the case of polymers and explosives or to phase transformation in metals within the temperature range from $A_{\mathrm{c} 1}$ to $A_{\mathrm{c} 3}$ [3]. The temperature measurements of specimens stretched at high strain rates (from $10^{-2}$ to $10^{3} \mathrm{~s}^{-1}$ ) can be accomplished by using several tech- niques, i.e. by the use of a thermocouple connected to an oscilloscope [4], by means of high-speed photography - registering the temperature changes on an acetate sheet covered with a heat-sensitive film [3, 5], or taking advantage of infrared radiometers $[6,7]$. Each of these methods possesses, however, some crucial disadvantages. The measurements with thermoelements are restricted both to the measuring junction of the thermocouples and the thermometric lag of the registration system. High-speed photography provides an image of the spatial distribution of heat on the surface of the specimen, but the obtained temperature values are depending on the contact time of a single plate with the examined material. On the other hand, the oscilloscope and radiometric measurements, although they give a possibility of a precise temperature measurement even with high registration frequency (up to 1000 pictures per second), are confined to several measuring points on the specimen. This causes a grow-

*Corresponding author: e-mail address: slawomir.kolodziej@us.edu.pl 
Table 1. The chemical composition of the Docol ${ }^{\circledR} 1200$ steel under investigation (in wt.\%)

\begin{tabular}{ccccccccccccccc}
\hline $\mathrm{C}$ & $\mathrm{Si}$ & $\mathrm{Mn}$ & $\mathrm{P}$ & $\mathrm{S}$ & $\mathrm{N}$ & $\mathrm{Cr}$ & $\mathrm{Ni}$ & $\mathrm{Cu}$ & $\mathrm{Al}$ & $\mathrm{Nb}$ & $\mathrm{V}$ & $\mathrm{B}$ & $\mathrm{Fe}$ \\
\hline 0.113 & 0.22 & 1.58 & 0.01 & 0.002 & 0.006 & 0.04 & 0.04 & 0.01 & 0.035 & 0.016 & 0.01 & 0.0002 & bal. \\
\hline
\end{tabular}

Table 2. Mechanical properties of the Docol ${ }^{\circledR} 1200$ steel in the as-received state complying with the values taken from manufactures data sheet

\begin{tabular}{ccc}
\hline Proof stress $\overline{\mathrm{PS}}(\mathrm{MPa})$ & Tensile strength $\overline{\mathrm{UTS}}(\mathrm{MPa})$ & Elongation $\overline{\mathrm{A}_{80}}(\%)$ \\
\hline 1210 & 1277 & 4.3 \\
\hline
\end{tabular}

ing interest in the use, for this purpose, of high-speed infrared thermographic cameras. Opportunities associated with the use of such cameras to monitor the temperature changes during high-speed tensile tests are described by Crump et al. [8] in the application for high-speed tensile tests of cross-ply glass fibre specimens with a stretching velocity of $5 \mathrm{~m} \mathrm{~s}^{-1}\left(\dot{\varepsilon} \sim 50 \mathrm{~s}^{-1}\right)$. Investigations with the use of infrared cameras were also carried out by Wojtaszek et al. [9] and Hellouin de Menibus et al. [10], who emphasized an intense temperature rise of specimens deformed at high deformation velocities within the range of plastic deformation.

The aim of this paper is to describe, how the strain rate influences the mechanical properties of a constructional dual-phase (DP) steel, with an ultimate tensile strength (UTS) ca. $1200 \mathrm{MPa}$, using for the deformation measurements a high-speed digital camera and making use of the non-contact optical 2D deformation measuring system ARAMIS ${ }^{\circledR}$, as well as the measurement and verification of the thermal effect, triggered by the plastic deformation. The tensile tests performed in this work were conducted, for comparative purposes, under quasi-static and dynamic conditions, in conjunction with the thermographic analysis in the gauge section, making use of an infrared camera. The performed fractographic analysis enabled the verification of cracking mechanisms of the investigated steel under studied strain rate conditions. Investigations of this type of steels under dynamic conditions are well grounded since the car body parts produced from them are destined for crumple zones, accumulating the impact energy of projected constructions.

\section{Experimental procedure}

The investigations were performed on a highstrength DP steel of the brand Docol ${ }^{\circledR} 1200$, derived from an industrial cast supplied by the Swedish steel company SSAB, usually dedicated to the automotive industry. The chemical composition of this steel is given in Table 1, whereas its structure and mechanical properties in the as-received state are

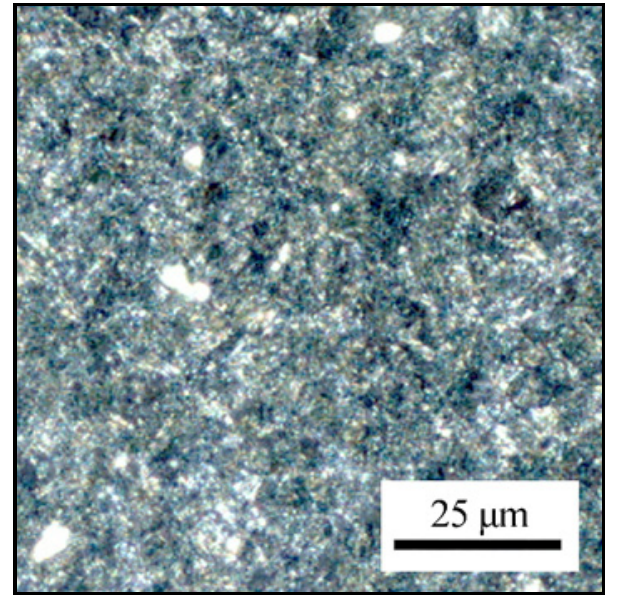

Fig. 1. The martensite-ferrite microstructure of the Docol ${ }^{\circledR}$ 1200 steel in the as-received state. $2 \%$ nital etch, magnification $500 \times$.

a)

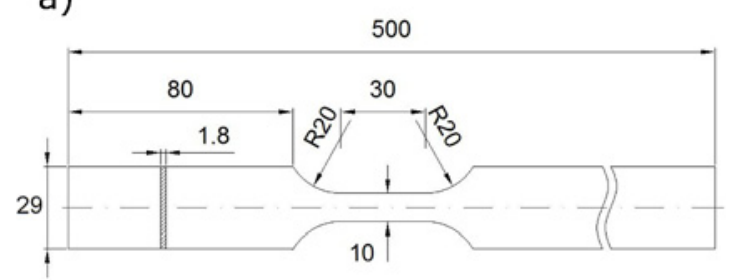

b)

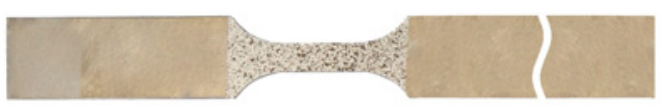

Fig. 2. The steel specimen under investigation: a) dimensions of the test specimen, b) the prepared specimen with a gray-scale pattern in the gauge length.

given in Fig. 1 and Table 2, respectively. The tensile tests were conducted at standard laboratory conditions at room temperature (ca. $21^{\circ} \mathrm{C}$ ) under quasistatic and dynamic conditions (Table 3 ). The tested 
Table 3. Parameters of stretching in the quasi-static and dynamic tensile tests for the specimens selected for detailed thermographic analysis

\begin{tabular}{lccc}
\hline Specimen & Stretching velocity $\left(\mathrm{m} \mathrm{s}^{-1}\right)$ & Stretching duration $(\mathrm{s})$ & Strain rate $\dot{\varepsilon}\left(\mathrm{s}^{-1}\right)$ \\
\hline QS1 & 0.0001 & 32.4 & $3.3 \cdot 10^{-3}$ \\
DS1 & 1 & 0.005575 & 33 \\
\hline
\end{tabular}
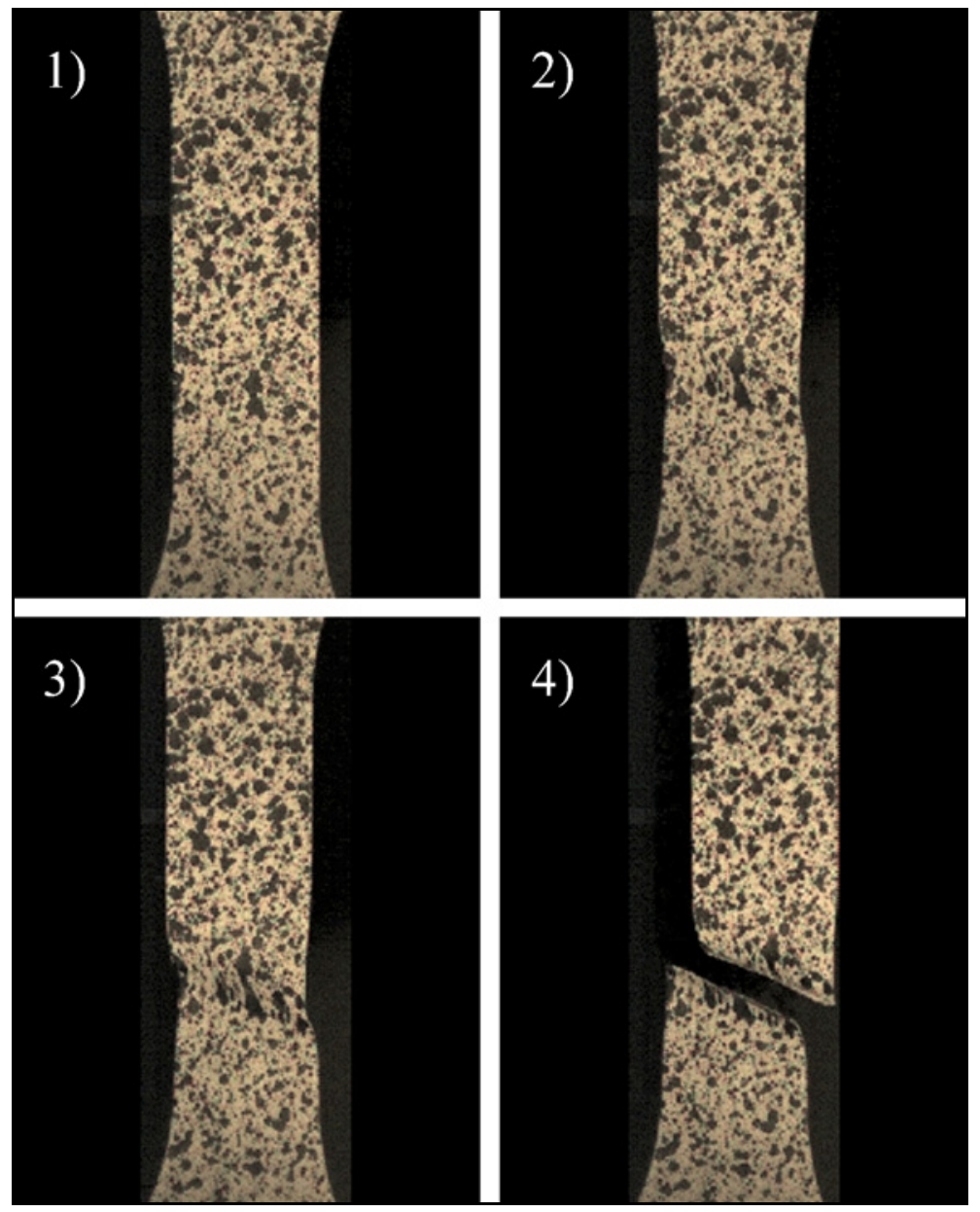

Fig. 3. Photographs of the gauge section of the specimen QS1 stretched with $v_{1}=0.0001 \mathrm{~m} \mathrm{~s}^{-1}$ in selected states of deformation: 1) origin of the deformation; 2) maximum deformation in the tensile direction - the start of the crack propagation; 3) before rupture; 4) after rupture.

specimens (Fig. 2a) were cut along the rolling direction (RD), according to the ISO 26203-2 standard. The investigations were performed at the Institute of Lightweight Engineering and Polymer Technology (ILK) at the Technical University Dresden (Germany), on a servo-hydraulic testing device INSTRON VHS $160 / 20$, intended for research works with the use of rapid crosshead movements, coupled with a highspeed digital camera Phantom 7.2 for the registration of shape deformation. The deformation measurements were based on the accurate comparison of digital images of the gray-scale pattern, covered on the gauge length of the test specimens (Fig. 2b). The calcula- tion of the strain values, based on the shape changes of the gray-scale pattern at the gauge length of the specimens, was carried out with the gray-scale correlation software ARAMIS ${ }^{\circledR}$ using the 2D Digital Image Correlation (DIC) method. The software divides the image of the grayscale pattern into various rectangular image details, so-called facets, of the user-defined size (here $12 \times 30$ pixels). The pattern is then identified and defined according to the grayscale grades and afterward correlated with appropriate areas on further images. Results from the DIC are the average values of strain $\left(\varepsilon_{\mathrm{av}}\right)$, as well as the spatial distribution of this strain in the specimen, indicating the minimum 
$\left(\varepsilon_{\min }\right)$ and maximum $\left(\varepsilon_{\max }\right)$ strain values. All deformation values mentioned in this paper are related to the strain in the RD. The metallographic observations were carried out on an Axio Observer optical microscope and a Supra 35 scanning electron microscope, both produced by Zeiss. The micrographic specimens were etched in $2 \%$ Nital, whereas the fracture surface of the specimens was grounded, before the observations, in ethyl alcohol using the ultrasonic method.

The thermographic measurements were realized using a VarioCAM ${ }^{\circledR}$ high-resolution thermographic system for the long-wave infrared spectral range of 7.5 to $14 \mu \mathrm{m}$ with a maximum resolution of $320 \times 240$ pixels, and an infrared frame rate of $50 \mathrm{~Hz}$. The accuracy of temperature measurements within the range from 0 to $100^{\circ} \mathrm{C}$ was $\pm 5 \mathrm{~K}$ with the temperature resolution of $80 \mathrm{mK}$. The description of the temperature changes was realized based on the values from 11 measurement points (13 in case of dynamical stretching), arranged symmetrically on the gauge length of the specimens. The points were designated with the letter $\mathrm{P}$ followed by consecutive numbers. Moreover, the maximum and minimum temperature values, as well as the average value of the material temperature in the whole gauge section of the specimens, had been determined.

\section{Results}

\subsection{Quasi-static tension}

During tensile tests performed with the stretching velocity $v_{1}\left(1 \times 10^{-4} \mathrm{~m} \mathrm{~s}^{-1}\left(\dot{\varepsilon}_{1}=3.3 \times 10^{-3} \mathrm{~s}^{-1}\right)\right)$ the recording frequency of the high-speed digital camera was stated to 20 frames per second. The optical registration of changes in the shape of the gray-scale pattern (Fig. 3) permitted to accomplish the deformation analysis in the gauge section of the specimens making use of the 2D-DIC method. The deformation versus time curves, concerning the results for a representative specimen (QS1), stretched with the velocity $v_{1}$, are plotted in Fig. 4 . The diagram was supplemented with a digital image of the gauge section of the tested specimen, containing a visualization of the spatial distribution of deformation in the analysed area, adjacent to the occurrence of the greatest local deformation directly preceding the initiation of cracking. In that case, due to the incoherence of the material surface, the program rejects the facets with highest deformations. Performing an analysis of the digital pictures from the high-speed camera, together with the results from the tensile tests, stress $(\sigma)-$ strain $(\varepsilon)$ curves were computed, taking into consideration the average strain values in the gauge section of the specimen (Fig. 5) and the maximum strain values detected (Fig. 6). Based on the elongation versus time

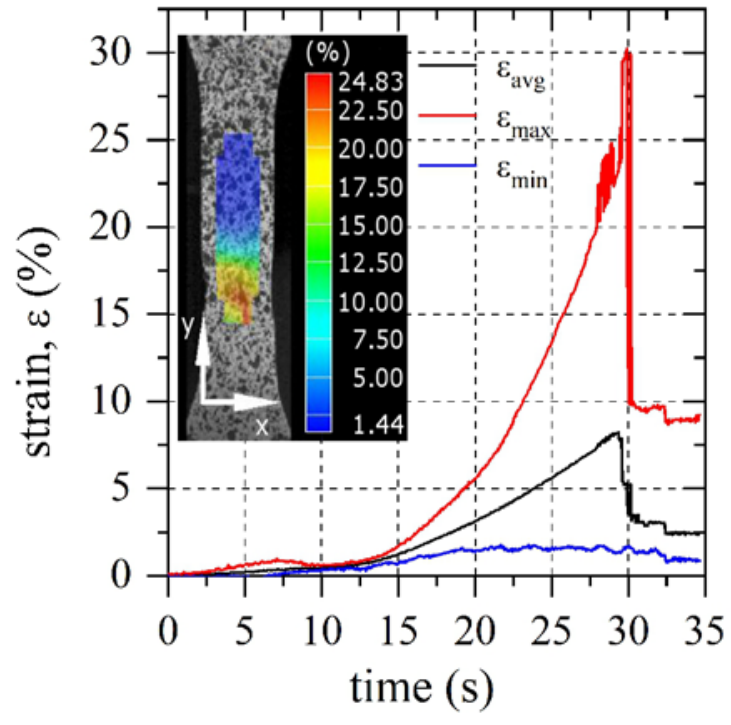

Fig. 4. The time-dependent deformation changes obtained for the Docol ${ }^{\circledR} 1200$ steel with the software ARAMIS ${ }^{\circledR}$ for the specimen QS1 tested at $0.0001 \mathrm{~m} \mathrm{~s}^{-1}$. In inset - deformation distribution in the gauge section of the specimen near the maximum registered deformation value.

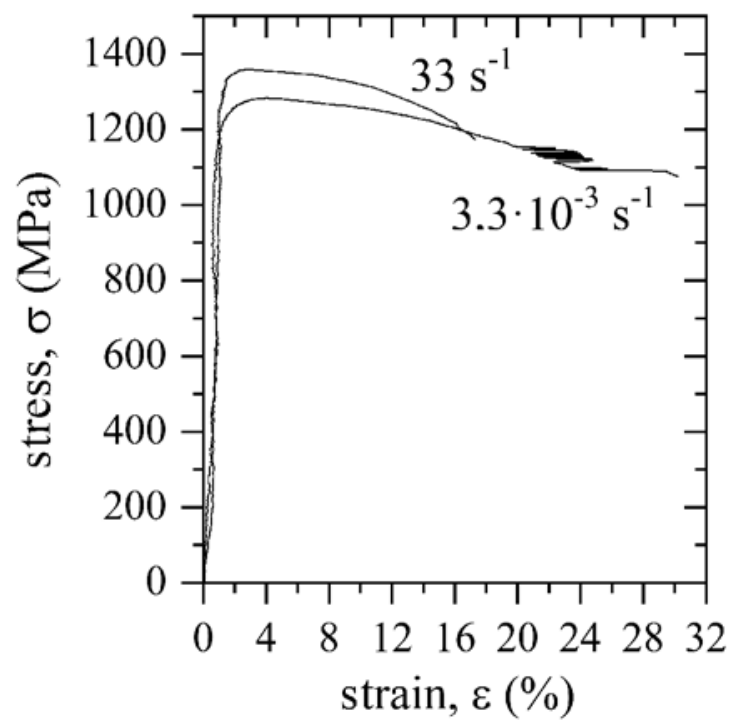

Fig. 5. Stress-strain curves of the Docol ${ }^{\circledR} 1200$ steel stretched with different strain rates (specimen QS1 and DS1). Strain values taken from average values in gauge area.

curves and the $\sigma-\varepsilon$ curves it can be estimated that the ultimate tensile strength for the statically stretched specimens was UTS $=1305 \pm 13 \mathrm{MPa}$ (Table 4). The average strain $\left(\varepsilon_{\mathrm{av}}\right)$ in the gauge section of the specimen stretched under quasi-static conditions was found to be $7.9 \pm 1.9 \%$, while the maximum registered strain 
Table 4. Mechanical properties of the Docol ${ }^{\circledR} 1200$ steel determined in quasi-static and dynamic tensile tests and the mean temperature values registered at the beginning of deformation and in the moment of rupture

\begin{tabular}{|c|c|c|c|c|c|c|c|c|c|}
\hline \multirow[t]{2}{*}{$\begin{array}{l}\text { Strain } \\
\text { rate, } \\
\left(\mathrm{s}^{-1}\right)\end{array}$} & \multirow[t]{2}{*}{ Specimen } & \multirow[t]{2}{*}{$\begin{array}{c}\text { UTS } \\
(\mathrm{MPa})\end{array}$} & \multicolumn{3}{|c|}{ Strain (\%) } & \multirow{2}{*}{$\frac{\begin{array}{c}\text { Initial } \\
\text { temperature } \\
\left({ }^{\circ} \mathrm{C}\right)\end{array}}{T_{0}}$} & \multicolumn{3}{|c|}{$\begin{array}{l}\text { Temperature at rupture } \\
\qquad\left({ }^{\circ} \mathrm{C}\right)\end{array}$} \\
\hline & & & $\varepsilon_{\min }$ & $\varepsilon_{\mathrm{av}}$ & $\varepsilon_{\max }$ & & $T_{\min }$ & $T_{\mathrm{av}}$ & $T_{\max }$ \\
\hline \multirow[t]{4}{*}{$3.3 \times 10^{-3}$} & QS1 & 1283 & 1.77 & 8.24 & 30.22 & 21.8 & 23.7 & 32.7 & 50.2 \\
\hline & QS2 & 1313 & 1.37 & 6.68 & 34.26 & 21.8 & 26.0 & 35.0 & 55.3 \\
\hline & QS3 & 1316 & 1.01 & 5.93 & 27.95 & 22.5 & 25.2 & 32.9 & 51.0 \\
\hline & QS4 & 1308 & 2.98 & 10.77 & 28.55 & 22.5 & 24.0 & 34.8 & 59.4 \\
\hline \multirow[t]{3}{*}{33} & DS1 & 1358 & 4.19 & 7.89 & 17.30 & 23.3 & 23.3 & 34.8 & 128.9 \\
\hline & DS2 & 1320 & 2.61 & 6.03 & 14.14 & 23.0 & 22.2 & 32.3 & 104.9 \\
\hline & DS3 & 1299 & 4.35 & 7.76 & 16.99 & 23.2 & 23.1 & 37.3 & 128.9 \\
\hline
\end{tabular}

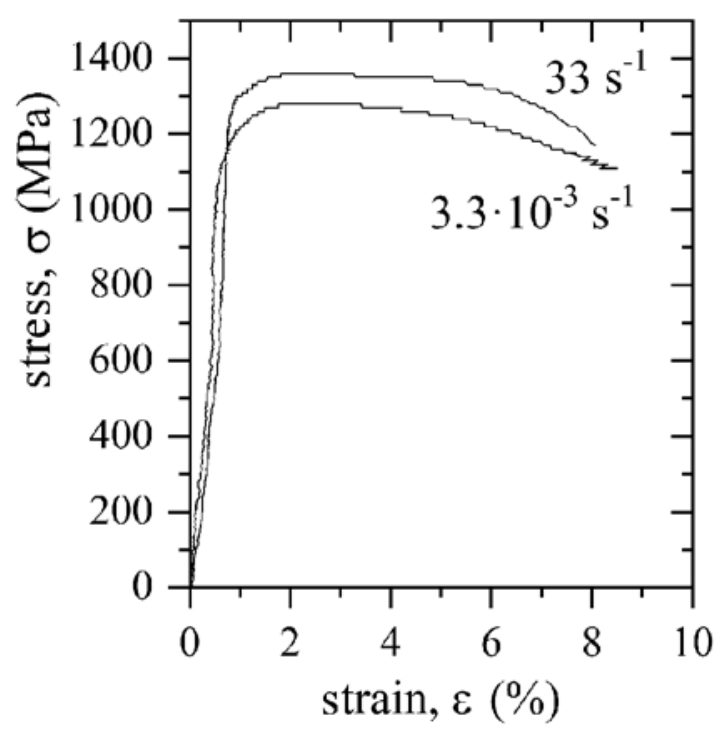

Fig. 6. Stress-strain curves of the Docol ${ }^{\circledR} 1200$ steel stretched with different strain rates (specimen QS1 and DS1). Strain values taken from the maximum values in gauge area.

values $\left(\varepsilon_{\max }\right)-30.2 \pm 2.5 \%$. At the instant, in which $\varepsilon_{\max }$ reaches the highest value, the minimum strain values $\left(\varepsilon_{\min }\right)$ were positive, ca. $1.8 \pm 0.7 \%$.

For the thermographic analysis, digital images of the gauge length of the specimen recorded during the tensile test were correlated with corresponding frames from the infrared camera (Fig. 7). For the tensile test performed with the strain rate $\dot{\varepsilon}_{1}$, which lasted $32.4 \mathrm{~s}$ (Table 3 ), the frame rate of the infrared camera was set to $25 \mathrm{~Hz}$. The obtained correlation of digital registration of deformation and the infrared registration was satisfactory. The temperature profiles, detected in all of the measurement points on the quasi-static stretched sample, are displayed on a chart (Fig. 8). In the initial phase of the tensile test, the tempera- a)

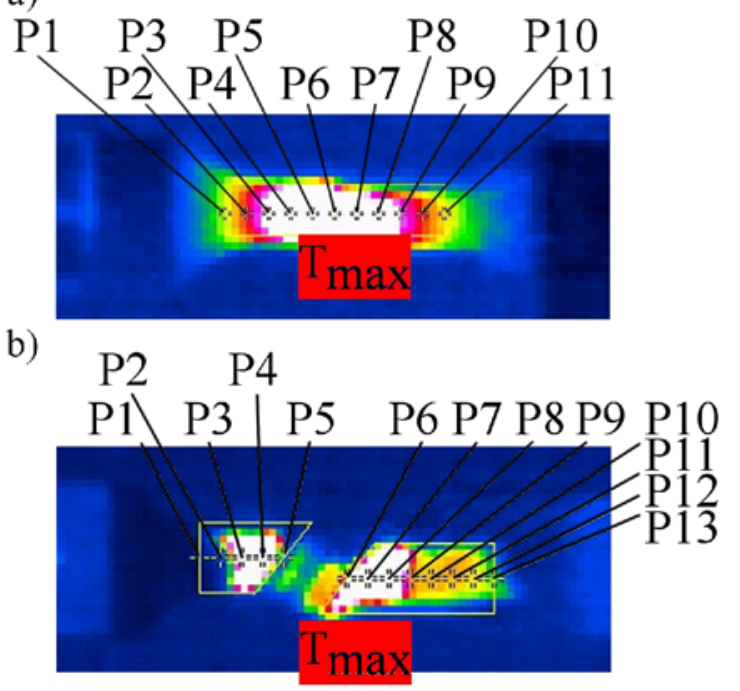

Fig. 7. Thermographic frames of the specimen stretched at a) $\dot{\varepsilon}_{1}$ and b) $\dot{\varepsilon}_{2}$ registered just after rupture of the tested specimens. Registered temperature values for a) are set on a graph in Fig. 8, whereas for b) in Table 5.

ture of the specimen surface was found to be approximately constant around $\sim 21-22^{\circ} \mathrm{C}$. After about $15 \mathrm{~s}$ of stretching force activity, the temperature rises in a monotone manner, whereby the most intense increase characterizes the plots representing the maximum temperature of the specimen and the temperature registered in the closest measurement points, i.e., P5 and P6. Although the temperature values, registered in the next points, were significantly lower, the temperature profiles detected on the whole gauge length of the specimen have a growing character. At the last stage of stretching (approx. $0.3 \mathrm{~s}$ before rupture), while the maximum temperature of the specimen reached $45.5^{\circ} \mathrm{C}$, a distinct temperature drop of $2.3^{\circ} \mathrm{C}$ was measured, giving a decrease of about $5 \%$ 
Table 5. Changes of the temperature values of the specimen stretched under dynamic conditions. The rows indicate values registered just before and after rupture of the specimen

\begin{tabular}{rccccccccccccc}
\hline \multicolumn{11}{c}{ Temperature $\left({ }^{\circ} \mathrm{C}\right)$} \\
\hline$T_{\max }$ & P1 & P2 & P3 & P4 & P5 & P6 & P7 & P8 & P9 & P10 & P11 & P12 & P13 \\
\hline 76.4 & 23.0 & 23.9 & 36.2 & 52.9 & 41.7 & 24.1 & 24.1 & 24.1 & 24.0 & 23.9 & 23.9 & 23.9 & 23.9 \\
128.9 & 23.4 & 25.7 & 56.7 & 78.4 & 26.4 & 24.1 & 24.1 & 24.1 & 23.9 & 23.9 & 23.9 & 23.9 & 23.9 \\
\hline
\end{tabular}

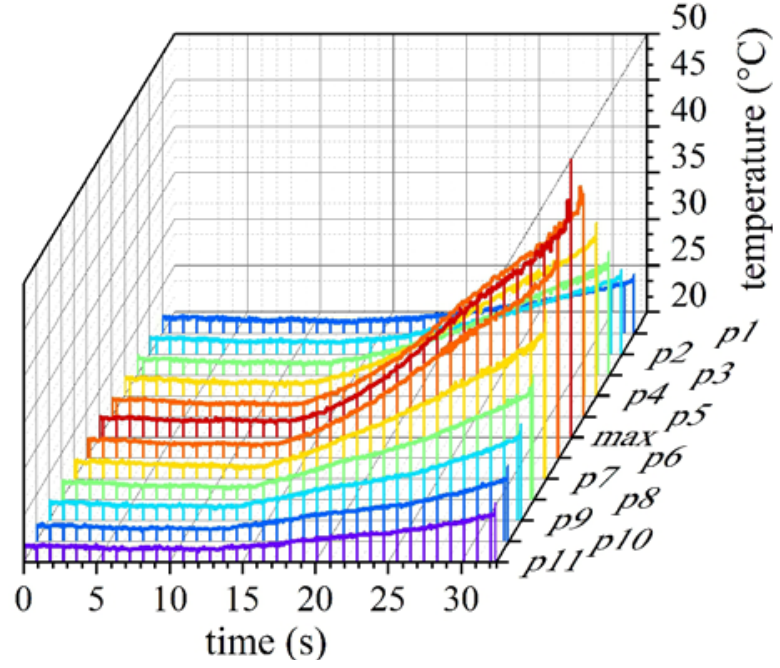

Fig. 8. Temperature indication in all measuring points stated with the maximum temperature in the gauge length of the specimen QS1 stretched at $\dot{\varepsilon}_{1}$.
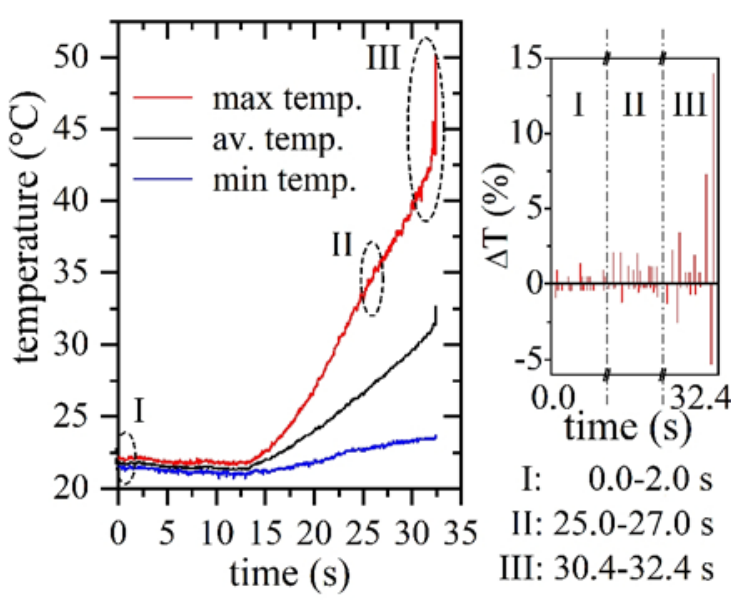

Fig. 9. Temperature distribution in the gauge length of the specimen QS1 stretched under quasi-static conditions with (in inset) calculated local fluctuations of maximum temperature in marked regions (I-III).

from the achieved maximum value (Fig. 9). A discernible temperature decrease was also observed in the nearest, neighboring to the site with the maximum temperature, measurement point $\mathrm{P} 5$. In the end stage of stretching, the average temperature values, measured at the gauge length of the specimen, stabilize at a relatively constant level. However, the rupture of the specimen causes an abrupt temperature rise on the whole gauge length. It was also stated that the decohesion of the specimens, stretched with the investigated deformation rates, proceeds across a line set by the points with the highest temperature value.

\subsection{Dynamic tension}

In the case of dynamic tensile tests performed with velocity $v_{2}=1 \mathrm{~ms}^{-1}\left(\dot{\varepsilon}_{2}=33 \mathrm{~s}^{-1}\right)$ the recording frequency of the high-speed digital camera was enlarged up to 80.000 frames per second. The optical images of the gray-scale pattern, for a representative specimen (DS1), stretched at these conditions are displayed in Fig. 10. The analysis of the elongation versus time diagram (Fig. 11) and the $\sigma-\varepsilon$ curves (Figs. 5, 6) indicates that the rise of strain rate in relation to $\dot{\varepsilon}_{1}$ causes an increase of the ultimate tensile strength UTS from $1305 \pm 13 \mathrm{MPa}$ to $1326 \pm 24 \mathrm{MPa}$ and a decrease of the average ultimate strain $\varepsilon_{\text {av }}$ from $7.9 \pm 1.9 \%$ to 7.2 $\pm 0.8 \%$, respectively. More pronounced changes were noted for maximum strain $\varepsilon_{\max }$, which drops from $30.2 \pm 2.5 \%$ to $16.1 \pm 1.4 \%$ (Table 4 ). Also higher values of the minimum strain, $\varepsilon_{\min }=3.7 \pm 0.8 \%$, were registered in the dynamic stretching conditions.

For the specimen stretched with the strain rate $\dot{\varepsilon}_{2}$, the stretching time until the moment of rupture was $t=0.005575 \mathrm{~s}$. Thus the used infrared camera was incapable of registering the temperature changes during the plastic deformation. The minimum delay between successive infrared frames was $0.02 \mathrm{~s}$, what enabled the registration of only one temperature record during the stretching process (Table 5). For comparative purposes, the average temperature of the specimen surface registered in the gauge length at the beginning of deformation $\left(T_{0}\right)$ and the average $\left(T_{\mathrm{av}}\right)$, minimum $\left(T_{\min }\right)$ and maximum $\left(T_{\max }\right)$ temperatures at the moment of rupture are displayed in Table 4 . It was stated that the highest temperature of the specimen stretched under quasi-static conditions amounts to $54.0 \pm 3.7^{\circ} \mathrm{C}$, whereas $T_{\max }$ of the dynamically stretched specimen reached $120.9 \pm 11.3^{\circ} \mathrm{C}$, giving a pronounced temperature rise, in relation to $T_{0}$, of ca. $32^{\circ} \mathrm{C}$ and ca. $98^{\circ} \mathrm{C}$, respectively. In the case of 

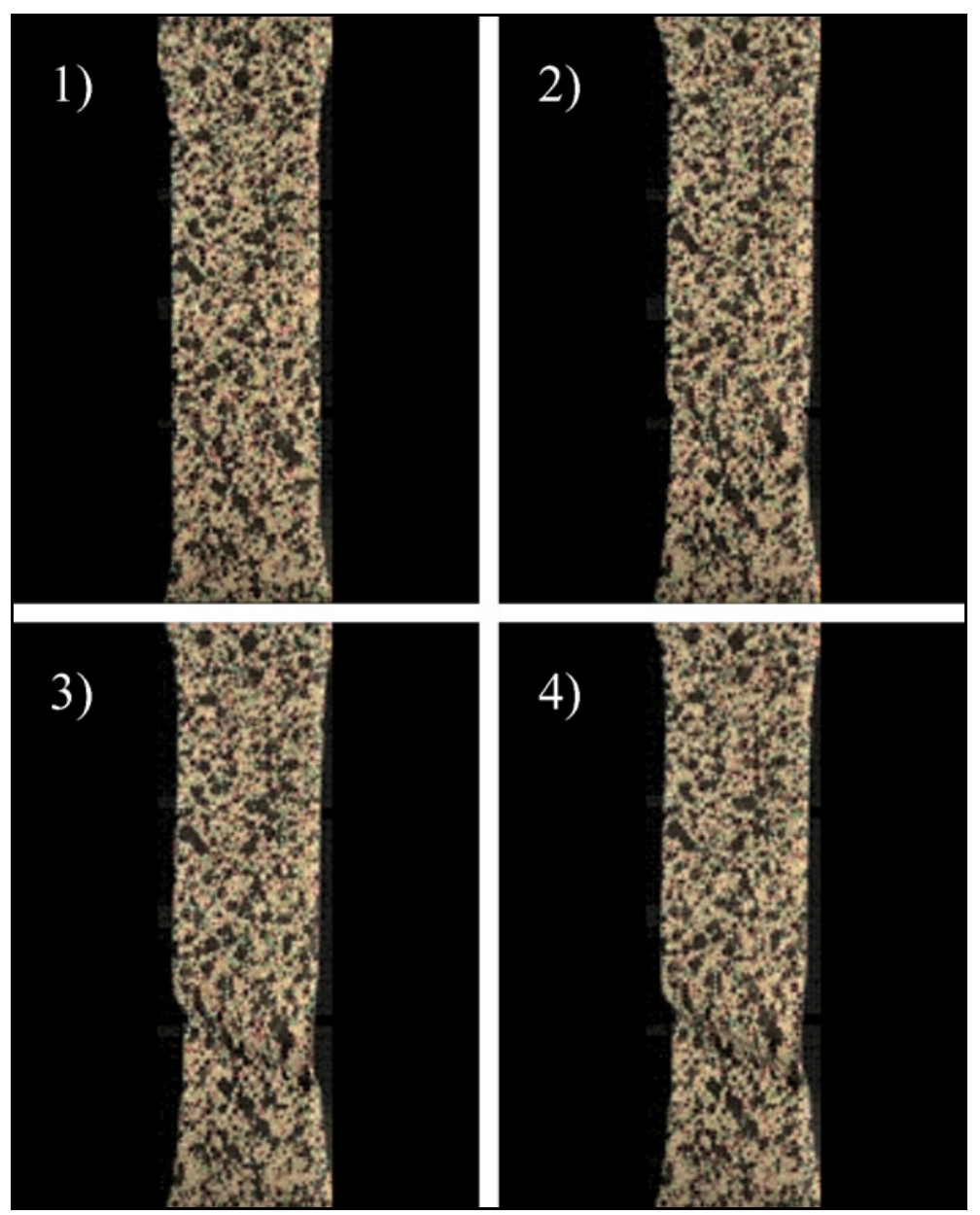

Fig. 10. Photographs of the gauge section of the tested specimen stretched with $v_{2}=1 \mathrm{~m} \mathrm{~s}^{-1}$ in selected states of deformation: 1) origin of the deformation; 2) maximum deformation in the tensile direction - the start of the crack propagation; 3) before rupture; 4) after rupture.

the average and minimum values, the temperature increases are, however, rather small. The effect of differentiation of the measured temperature increments is however attributed, among others, to the heterogeneity of the temperature field in the gauge section of the investigated specimen, the strain localization, as well as - probably to the limited sensitivity of the infrared camera - to the rapid movement of the investigated specimen during stretching and synchronization of the registered image with the real temperature value in the selected measurement points.

\section{Discussion}

Tensile investigations, performed on samples from the Docol ${ }^{\circledR} 1200$ steel, carried out in the investigated plastic deformation conditions, together with concomitant microscopic observations, indicated that the great mechanical properties in the as-received state of the steel are mainly determined by the finegrained structure, formed in the thermomechanical

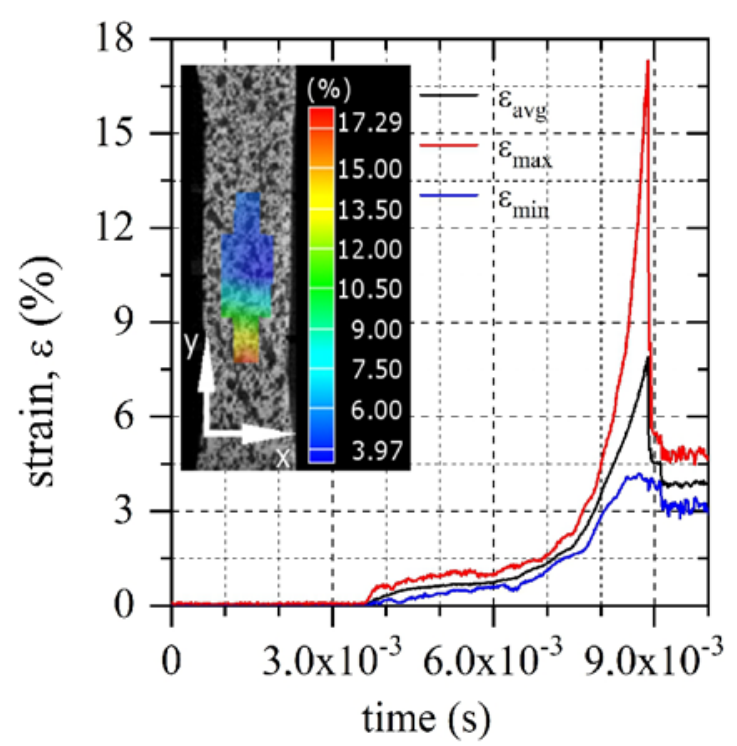

Fig. 11. The time-dependent deformation changes obtained for the Docol ${ }^{\circledR} 1200$ steel with the software ARAMIS ${ }^{\circledR}$ for the specimen tested at $1 \mathrm{~m} \mathrm{~s}^{-1}$. 
treatment process. High strength and relatively low values of elongation are the effects of the dual-phase martensitic-ferritic structure, containing a low amount (about $10 \%$ ) of pro-eutectoid ferrite (Fig. 1). The growing deformation rate indicated only a slight increase in strength and decrease of plasticity, however, a considerable rise of its $\varepsilon_{\text {min }}$ value from ca. 1.8 to ca. $3.7 \%$ was observed (Table 4 ), thus suggesting a change in the fragile fracture mechanism of the basic martensitic structure, with a minimum amount of the ductile ferrite phase. The shape of the $\sigma-\varepsilon$ curves, obtained in the case of dynamic tensile tests, indicates the tendency of the tested material to absorb a considerable amount of the impact energy (Figs. 5, 6). An analysis of the results of investigations performed by Cao et al. [11] on the DP 800 steel has proved that an increase of $\dot{\varepsilon}$ from $10^{-4}$ to $10^{2} \mathrm{~s}^{-1}$ leads to an increase of UTS by about $10 \%$ and a drop of deformation by about $34 \%$. The Docol ${ }^{\circledR} 1200$ steel under investigation displays a similar dependence of the indices of mechanical properties, whereby, in the course of impact stretching of this steel at $\dot{\varepsilon}_{2}$, the obtained values of plastic deformation were nearly equal to those of the DP 800 steel. However, its strength was significantly higher.

The thermographic analysis performed during the tensile tests permitted the determination of the temperature changes in the gauge length of the tested samples. It is well known that an increased deformation rate decreases the dissipation of the deformation energy, resulting in an enhanced localization of the energy, and thus also in a rise of temperature of the tested sample [10]. In the course of stretching of the tested samples under quasi-static and dynamic conditions, the observed temperature rise within the range of plastic deformation was $32^{\circ} \mathrm{C}$ and $98^{\circ} \mathrm{C}$, respectively. Due to a limited recording frequency of the applied infrared camera, a detailed thermographic analysis was carried out only on the sample stretched under quasi-static conditions (Fig. 9). In the analysed measuring points $(\mathrm{P} 5 \rightarrow \mathrm{P} 1$ and $\mathrm{P} 6 \rightarrow \mathrm{P} 11)$, the detected increase in temperature is lower and delayed. These changes are of an exponential character, what is related to the time dependence of the deformation energy dissipation. A distinct increase of temperature in the gauge section of the tested specimens may also justify the considerable high value of the local deformation of the samples stretched at $\dot{\varepsilon}_{1}$. This may be caused by the fact, that the largest local deformations in DP steels are being observed in ferrite, particularly in the zones of ferrite-martensite interfaces [12, 13], which are the fracture initiation zones $[12,14]$. In the course of stretching with the rate $\dot{\varepsilon}_{1}$, the temperature rise of the tested sample can intensify the diffusion of carbon to dislocations and phase boundaries, causing the effect of dynamic ageing [11]. The local depletion of carbon in ferrite and martensite may also lead to their plasticization and deformation. As the diffusion
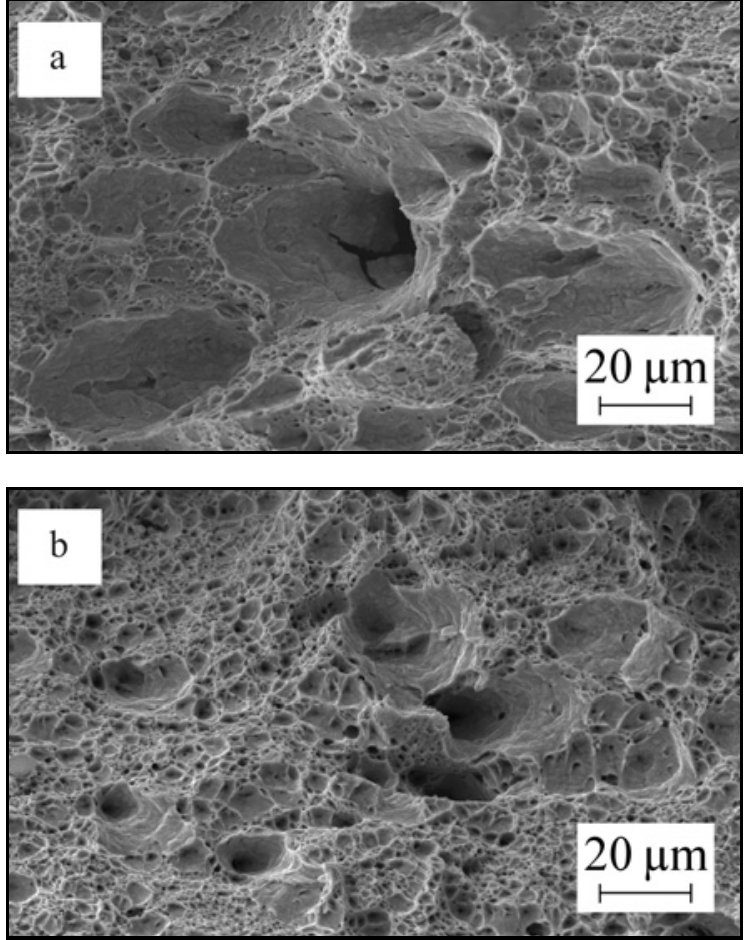

Fig. 12. The moderately fragile fracture of the Docol ${ }^{\circledR}$ 1200 steel under investigation after a) the quasi-static tensile test, b) the dynamic tensile test. Magnification $2000 \times$.

is a time-dependent process, this effect is not so distinct in the course of dynamic stretching at the strain rate $\dot{\varepsilon}_{2}$. This may be possibly due to only a slight difference in the mechanical properties, connected with the increased deformation rate. However, in DP steels containing high amounts of martensite, this phase is also subjected to deformation, even in a degree comparable to that of ferrite $[14,15]$ and thus also to fracture [16].

In the case of the quasi-static tensile test, it has also been found that within the time of $0.24 \mathrm{~s}$ preceding the moment of rupture, the maximum temperature of the sample drops down by about $5 \%$ in relation to the maximum value. The analysis of the quantity of this drop $\Delta T$, calculated as the difference between the local minimum and maximum of registered temperature values, in the III stage of stretching (Fig. 9) and its comparison with the values calculated for stages I and II permits to conclude that this effect is most probably not a result of the measuring error of the infrared camera, but that it is physically connected with changes in the energy dissipation in the deformed material as well as its microstructural alterations caused by the change of the brittle fracture mechanism. The performed fractographic investigations of the ruptured samples confirm the hypothetical transition of this cracking mechanism, showing an intermediate fracture surface with a considerable amount of zones with a ductile character 


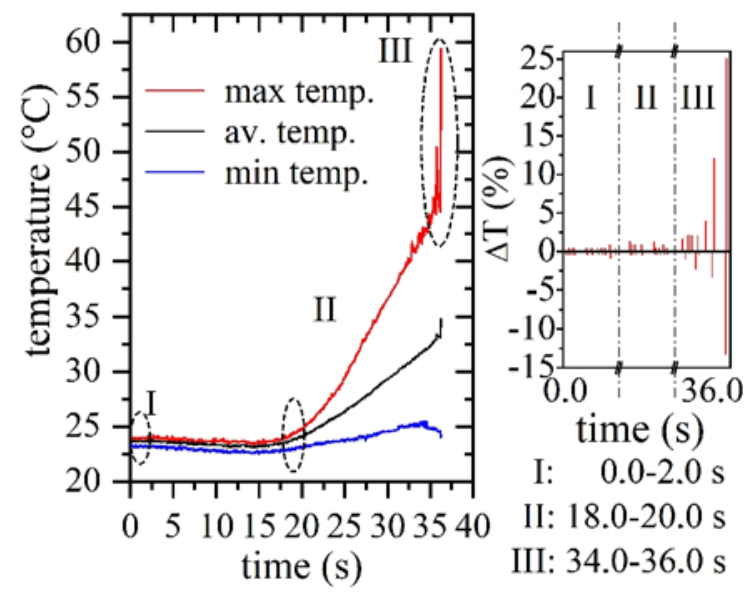

Fig. 13. Temperature distribution in the gauge length of the specimen QS4 from the Docol ${ }^{\circledR} 1200$ steel stretched under quasi-static conditions with (in inset) calculated local fluctuations of maximum temperature in marked regions $(\mathrm{I} \div \mathrm{III})$.

(Fig. 12). This can be merely observed in both, the quasi-static stretched sample (Fig. 12a) and the dynamically stretched sample (Fig. 12b). Moreover, similar thermal effects have been observed in the case of other stretched samples of the tested steel (Fig. 13).

In conclusion, it should be emphasized, that the thermal effect associated with the temperature increase of the plastically deformed specimens is generally known and through analysed in the literature $[10,17]$. However, the use of high-speed thermographic cameras shed new light on this problem. Primarily a temperature decrease was observed during stretching of Armco iron [18, 19] and some metallic alloys [20, 21] with strain rates ranging from $10^{-4}$ to $10^{-1} \mathrm{~s}^{-1}$ in the regime of elastic deformation. Thus it was attributed to the thermoelastic effect. In work [19] also a temperature decrease preceding the intense increase just before the specimens rupture was registered, however, not discussed. Such an effect was also observed by Hyll et al. [22] in the process of stretching sack paper samples with a strain rate equal to $10^{-3} \mathrm{~s}^{-1}$. Here, the temperature drop was addressed to the rate of heat generation due to plastic deformation which could be lower than the heat loss due to radiation and convection but also to the possible evaporation of moisture, which is also common in this kind of materials. Thus, we assume that the verification of this effect requires further investigations, applying for thermographic measurements an infrared camera capable for a precise analysis of temperature changes in time periods of the order $10^{-4}$ to $10^{-5} \mathrm{~s}$. Thus, it will be possible to investigate the temperature changes in samples stretched at an even higher deformation rate, similar to that appropriate for vehicle crash tests.

\section{Conclusions}

The performed thermographic investigations of the Docol ${ }^{\circledR} 1200$ construction steel samples, stretched under quasi-static and dynamic conditions, lead to the following conclusions:

1. The applied investigation technique permits a complex analysis of deformation and temperature changes observed at the surface of the tested steel samples, stretched under quasi-static and dynamic conditions.

2. An increase of the deformation rate within the range from $\dot{\varepsilon}_{1}$ to $\dot{\varepsilon}_{2}$ results in an increase of tensile strength from 1305 to $1326 \mathrm{MPa}$, respectively, and an inconsiderable decrease of deformation $\varepsilon_{\mathrm{av}}$ from 7.9 to $7.2 \%$.

3. The registered temperature increase of the samples stretched quasi-statically at the rate $\dot{\varepsilon}_{1}$ amounted to about $32^{\circ} \mathrm{C}$ and that of the sample stretched dynamically at the rate $\dot{\varepsilon}_{2}$ was about $98^{\circ} \mathrm{C}$.

4. The thermographic measurements revealed, in the quasi-statically stretched specimens, an evident drop in temperature up to about $14 \%$ of the maximum value before the moment of rupture.

5 . The ultimate verification of the observed effect of temperature decrease in the final stretching stage of the tested steel samples requires further thermographic investigations, using an infrared camera with a considerably higher than $50 \mathrm{~Hz}$ recording frequency, together with complementary fractographic investigations.

\section{Acknowledgements}

The experiments were realized during a scientific internship of S. K. in the Institute of Lightweight Engineering and Polymer Technology (ILK) in Dresden. The authors would also like to thank K. Golombek from the Institute of Engineering Materials and Biomaterials of the Silesian University of Technology for his help with the SEM investigations.

\section{References}

[1] Şerban, D. A., Weber, G., Marşavina, L., Silberschmidt, V. V., Hufenbach, W.: Polym. Test., 32, 2013, p. 413. doi:10.1016/j.polymertesting.2012.12.002

[2] Wojtaszek, M., Sleboda, T., Czulak, A., Weber, G., Hufenbach, W.: Arch. Metall. Mater., 58, 2013, p. 1261. doi:10.2478/amm-2013-0145

[3] Swallowe, G. M., Field, J. E., Horn, L. A.: J. Mater. Sci., 21, 1986, p. 4089. doi:10.1007/BF02431656

[4] Chou, S. C., Robertson, K. D., Rainey, J. H.: Exp. Mech., 13, 1973, p. 422. doi:10.1007/BF02324886

[5] Coffey, C. S., Jacobs, S. J.: J. Appl. Phys., 52, 1981, p. 6991. doi:10.1063/1.328664

[6] Macdougall, D. A. S., Harding, J.: Int. J. Impact. Eng., 21, 1998, p. 473. doi:10.1016/S0734-743X(98)00007-4 
[7] Buckley, C. P., Harding, J., Hou, J. P., Ruiz, C., Trojanowski, A.: J. Mech. Phys. Solids, 49, 2001, p. 1517. doi:10.1016/S0022-5096(00)00085-5

[8] Crump, D. A., Dulieu-Barton, J. M., Fruehmann, R. K.: In: Proceedings of ECCM15. Ed.: Quaresimin, M. Padova, University of Padova 2012, p. 1. ISBN: 978-888878533-2

[9] Wojtaszek, M., Śleboda, T., Czulak, A., Weber, G., Hufenbach, W. A.: In: Proceedings of 23rd International Conference on Metallurgy and Materials, Metal 2014. Ostrava, TANGER 2014, p. 1405.

ISBN: 978-80-87294-54-3

[10] Hellouin de Menibus, A., Auzoux, Q., Besson, J., Crépin, J.: J. Nucl. Mater., 454, 2014, p. 247. doi:10.1016/j.jnucmat.2014.08.011

[11] Cao, Y., Ahlström, J., Karlsson, B.: J. Mater. Res. Technol., 4, 2015, p. 68. doi:10.1016/i.jmrt.2014.11.001

[12] Sirinakorn, T., Wongwises, S., Uthaisangsuk, V.: Mater. Design, 64, 2014, p. 729. doi:10.1016/i.matdes.2014.08.009

[13] Zhou, J., Gokhale, A. M., Gurumurthy, A., Bhat, S. P.: Mater. Sci. Eng. A, 630, 2015, p. 107. doi:10.1016/j.msea.2015.02.017
[14] Saai, A., Hopperstadt, O. S., Granbom, Y., Lademo, O.-G.: Procedia Mater. Sci., 3, 2014, p. 900. doi:10.1016/j.mspro.2014.06.146

[15] Ghadbeigi, H., Pinna, C., Celotto, S., Yates, J. R.: Mater. Sci. Eng. A, 527, 2010, p. 5026. doi:10.1016/j.msea.2010.04.052

[16] Wang, W., Wei, X.: Int. J. Mech. Sci., 67, 2013, p. 100. doi:10.1016/j.ijmecsci.2012.12.011

[17] Chrysochoos, A., Louche, H.: Int. J. Eng. Sci., 38, 2000, p. 1759. doi:10.1016/S0020-7225(00)00002-1

[18] Plekhov, O. A., Naimark, O. B., Saintier, N., Palin-Luc, T.: Tech. Phys., 54, 2009, p. 1141. doi:10.1134/S1063784209080088

[19] Kostina, A., Iziumova, A., Plekhov, O.: Fracture Struct. Integrity, 27, 2014, p. 28. doi:10.3221/IGF-ESIS.27.04

[20] Oliferuk, W., Maj, M., Litwinko, R., Urbański, L.: Eur. J. Mech. A-Solid., 35, 2012, p. 111. doi:10.1016/j.euromechsol.2011.08.007

[21] Rešković, S., Jandrlić, I., Vodopivec, F.: Metalurgija, 55, 2016, p. 157.

[22] Hyll, C., Vomhoff, H., Nygårds, M.: Nord. Pulp. Pap. Res. J., 27, 2012, p. 329. doi:10.3183/NPPRJ-2012-27-02-p329-334 